\title{
PARQUE NATURAL MUNICIPAL DE NOVA IGUAÇU: Um peculiar patrimônio geológico-geomorfológico na Baixada Fluminense, RJ
}

\author{
PARQUE NATURAL MUNICIPAL DE NOVA IGUAÇU: a peculiar geological-geomorphological \\ heritage in the Baixada Fluminense, RJ
}

Flávia Lopes Oliveira

Doutoranda do PPGEO-UERJ ${ }^{1}$ - flavialopes@oi.com.br

Nadja Maria Castilho da Costa

Professora Adjunta do IGEOG-UERJ - nadjacastilho@gmail.com

\begin{abstract}
Resumo
O Parque Natural Municipal de Nova Iguaçu, localizado na Baixada Fluminense do Estado do Rio de Janeiro é uma Unidade de Conservação com peculiar característica, pois abriga rochas e feições raras da geodiversidade brasileira, que indicam a possível ocorrência de processos vulcânicos de aproximadamente 70 milhões de anos. 0 presente artigo apresenta um relato dos principais trabalhos que discutem a existência ou não do chamado Vulcão de Nova Iguaçu e cita pontos da geodiversidade do Parque que fazem dele um importante patrimônio geológico-geomorfológico, buscando assim, contribuir para a sua geoconservação.
\end{abstract}

Palavras-chave: Geodiversidade, Patrimônio Geológico-geomorfológico, Vulcão de Nova Iguaçu, Unidade de Conservação.

\section{Abstrat}

The Parque Natural Municipal de Nova Iguaçu, located in the Baixada Fluminense region of the State of Rio de Janeiro is a Protected Area with peculiar characteristic, it houses rocks and rare Brazilian geodiversity features, which indicate the possible occurrence of volcanic processes approximately 70 million years. This article presents an account of the major works that discuss whether or not the so-called Nova Iguaçu Volcano and cites points of geodiversity of the park that make it an important geological and geomorphological heritage, thus seeking to contribute to their geoconservation.

Keywords: Geodiversity, Geological-geomorphological Heritage, Nova Iguaçu Volcano, Protected Area.

\footnotetext{
${ }^{1}$ Bolsista da Fundação de Amparo à Pesquisa do Estado do Rio de Janeiro - FAPERJ
} 


\section{INTRODUÇÃO}

A hipótese da existência de um vulcão em Nova Iguaçu, Baixada Fluminense do Estado do Rio de Janeiro, tem aguçado a curiosidade de muitas pessoas, ao longo dos anos, para visitar o Parque Natural Municipal de Nova Iguaçu (PNMNI), (figura 1). Não somente a curiosidade dos estudiosos das geociências, mas também de leigos no assunto que ficam entusiasmados pela ideia de conhecerem um vulcão brasileiro, mesmo este não estando mais em atividade.

\section{Localização do Parque Natural Municipal de Nova Iguaçu-RJ}

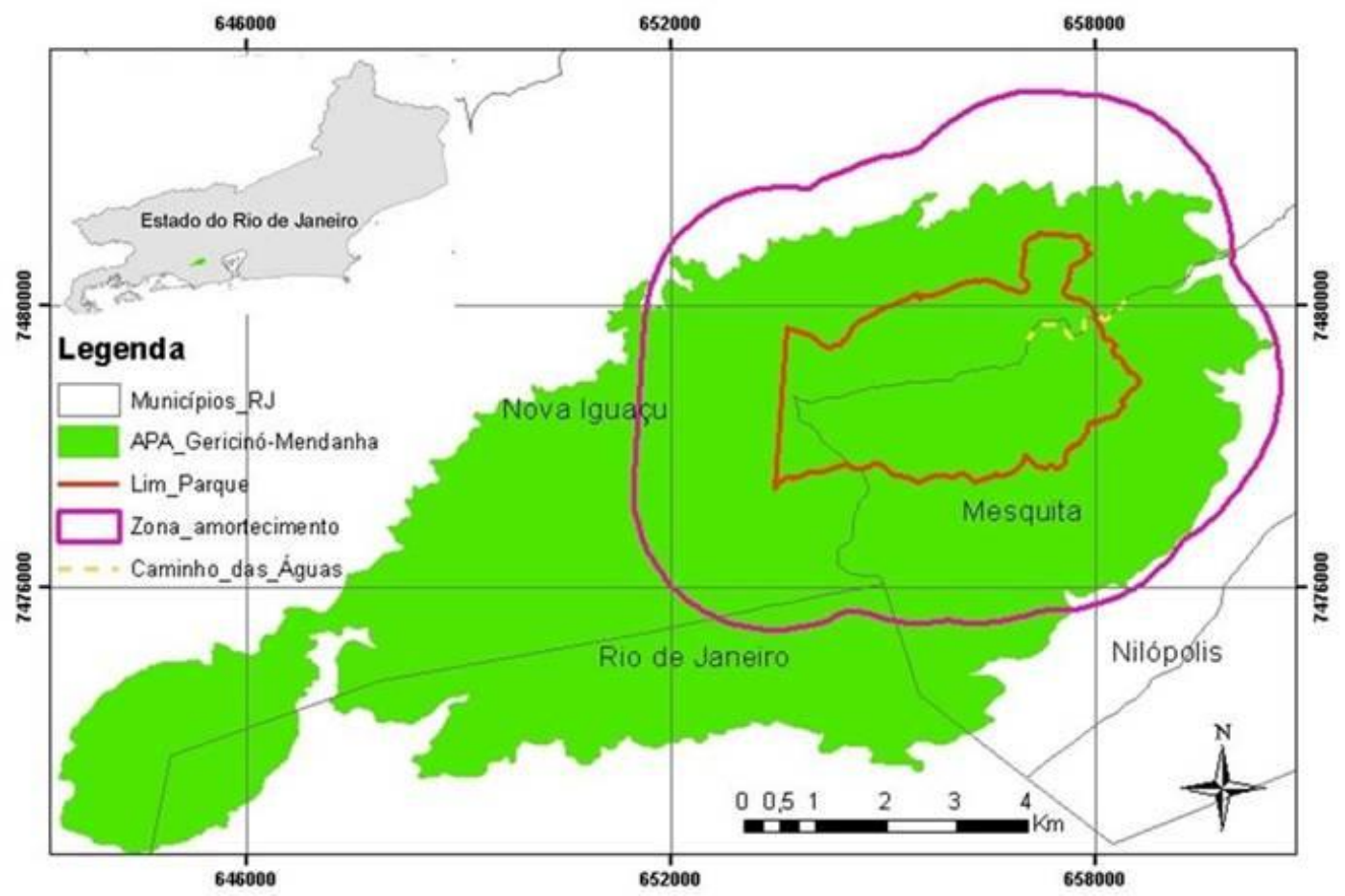

Figura 1 - Localização da área de estudo.

Porém, é importante ressaltar que, além das feições geológicas peculiares que indicam a possibilidade de ocorrências vulcânicas antigas no PNMNI, existe, também, um maravilhoso ambiente natural e cultural para ser contemplado e utilizado pelo visitante, com a presença de cachoeiras, piscinas 
naturais, espécies bióticas raras e arquitetura do século $\mathrm{XIX}^{2}$, que fazem desta Área Protegida um geossítio ainda mais especial.

Entretanto, apesar de uma diversidade de riquezas naturais e culturais, 0 presente artigo tem como finalidade focar na geodiversidade do PNMNI, relatando os principais trabalhos que discutem a existência ou não do chamado Vulcão de Nova Iguaçu e citando pontos da geodiversidade ao longo do Caminho das Águas, nome popular dado por acompanhar a direção do rio Dona Eugênia, é conhecido, também, como Estrada da Cachoeira, sendo esta a principal via de circulação do Parque (figuras $1 ; 2$ ).

\section{Área de Estudo}

O PNMNI (figura 1) é uma Unidade de Conservação (UC) criada em 05 de junho de 1998 pelo Decreto Municipal no 6.001. Está localizado na Baixada Fluminense, entre os Municípios de Mesquita e Nova Iguaçu, no Estado do Rio de Janeiro, mais precisamente na Serra de Madureira em sua vertente iguaçuana e faz parte da Área de Proteção Ambiental (APA) do GericinóMendanha, que abriga juntamente com os demais remanescentes florestais que recobrem toda a Serra do Mar, um importante remanescente florestal no Estado do Rio de Janeiro, sendo o maciço do Gericinó-Mendanha declarado como Reserva da Biosfera da Mata Atlântica, homologada pela Organização das Nações Unidas para a Educação, a Ciência e a Cultura (UNESCO), em 1992.

No Parque destacam exemplos de flora e fauna da Mata Atlântica, ainda preservados, tais como: Ipê-amarelo (Tabebuia sp), Tiê-preto (Tachyphonus coronatus), Beija-flor-de-fronte-violeta (Thalurania glaucopis), Saíra-de-setecores (Tangara seledon) e Caxinguelê (Sciurus ingrami), (PREFEITURA DA CIDADE DE NOVA IGUAÇU, 2000). Entretanto, atualmente, aproximadamente $70 \%$ da área da Unidade encontram-se coberta por vegetação em diferentes estágios de conservação, e o restante apresenta áreas com pastagens

\footnotetext{
${ }^{2}$ Casarão da Fazenda Dona Eugênia. Segundo alguns historiadores, trata-se do prédio mais antigo no Município de Nova Iguaçu que ainda permanece de pé, atraindo a atenção dos visitantes do PNMNI (PREFEITURA DA CIDADE DE NOVA IGUAÇU, 2000).
} 
degradadas e sujeitas a incêndios anuais, o que atrai a invasão de gado, retardando a recuperação por reflorestamento.

Além de sua rica biodiversidade o PNMNI apresenta, também, uma rica e peculiar geodiversidade, contendo feições de formação antiga, com aproximadamente 70 milhões de anos (MOTOKI; MOTOKI, 2011; MOTA et al. 2012), que indicam a possibilidade da existência de processos vulcânicos e/ou subvulcânicos no local, a exemplo: afloramento de sienito, diques de traquito, bombas vulcânicas e brechas piroclásticas; o que faz desse Parque um relevante geossítio (DRM, 2014).

O Parque possui uma área de 1.100 hectares e sua altitude oscila entre $150 \mathrm{~m}$ na entrada da Unidade e $956 \mathrm{~m}$ no marco sudoeste, próximo ao pico do Gericinó; tendo uma zona de amortecimento de dois quilômetros (figura 1), de acordo com o seu Plano de Manejo (PREFEITURA DA CIDADE DE NOVA IGUAÇU, 2000).

O principal acesso à UC se dá através da Estrada da Cachoeira, no Bairro da Coréia, Município de Mesquita. Em uma distância de $3 \mathrm{~km}$ a partir do bairro, encontra-se o portão do Parque, coordenadas UTM 658426 E / 7480099 $\mathrm{N}$, e, em cerca de $1,5 \mathrm{~km}$, sua sede, coordenadas UTM $657836 \mathrm{E} / 7479776 \mathrm{~N}$ - fuso 23 Sul / WGS 84 (figura 2).

\section{GEOPATRIMÔNIO: bases conceituais}

Originada do latim, a palavra patrimônio significa recebido do pai, patri: pai e monium: recebido, ou seja, algo que foi herdado pela geração atual e poderá ser passado para as gerações futuras, mas para que isso aconteça torna-se fundamental a proteção.

A preocupação mundial com a proteção patrimonial natural teve como marco os seguintes eventos: a Convenção para a Proteção da Flora, da Fauna e das Belezas Panorâmicas Naturais dos Países da América, em Washington, 1940; a Convenção de Argel para a Conservação da Natureza e dos Recursos Naturais, em Argel, 1968 e a Convenção de Proteção ao Patrimônio Mundial, 
Cultural e Natural, promovida pela UNESCO, em Paris, 1972. Este último objetivou, principalmente, identificar os sítios culturais e naturais mundiais, de interesse excepcional e de valor universal, de modo que sua proteção seja considerada responsabilidade de toda a humanidade.

Para fins de Convenção, foram considerados como patrimônio natural, segundo a UNESCO (1972):

\begin{abstract}
Os monumentos naturais constituídos por formações físicas e biológicas ou por grupos de tais formações com valor universal excepcional do ponto de vista estético ou científico;

As formações geológicas e fisiográficas e as zonas estritamente delimitadas que constituem habitat de espécies animais e vegetais ameaçadas, com valor universal excepcional do ponto de vista da ciência ou da conservação;

Os locais de interesse naturais ou zonas naturais estritamente delimitadas, com valor universal excepcional do ponto de vista da ciência, conservação ou beleza natural (UNESCO, 1972, Seção I, Artigo $\left.2^{\circ}\right)$.
\end{abstract}

Ou seja, segundo a UNESCO (1972), é considerado patrimônio natural da humanidade, dentre outros, as formações naturais abióticas que constituem substrato para o desenvolvimento da vida na Terra de espécies animais e vegetais ameaçadas; como também, os locais delimitados com valor universal excepcional do ponto de vista da ciência, conservação ou beleza natural.

No Brasil, foi criado em 1937, o Instituto de Patrimônio Histórico e Artístico Nacional (IPHAN) ${ }^{3}$, e tem como objetivo a proteção do patrimônio nacional material e imaterial, enquadrando o patrimônio natural como um setor técnico especializado que lida mais diretamente com elementos da natureza, os quais constituem a matéria-prima da produção cultural.

Para o IPHAN (2014), a preservação do patrimônio cultural exige, mesmo de forma sucinta, conhecimentos ligados ao meio físico e biológico, como geologia, paleontologia, espeleologia, hidrologia, biologia e ecologia.

$\mathrm{Na}$ Constituição Brasileira (1988), ainda que atrelada ao conceito de patrimônio cultural, já previa a proteção do bem natural nacional:

Constituem patrimônio cultural brasileiro os bens de natureza material e imaterial, tomados individualmente ou em conjunto, portadores de

\footnotetext{
${ }^{3}<$ http://portal.iphan.gov.br/portal/montarPaginalnicial.do $>$
} 
referência à identidade, à ação, à memória dos diferentes grupos formadores da sociedade brasileira, nos quais se incluem:

I - as formas de expressão;

II - os modos de criar, fazer e viver;

III - as criações científicas, artísticas e tecnológicas;

IV - as obras, objetos, documentos, edificações e demais espaços destinados às manifestações artístico-culturais;

$\mathrm{V}$ - os conjuntos urbanos e sítios de valor histórico, paisagístico, artístico, arqueológico, paleontológico, ecológico e científico (BRASIL, 1988, Seção II, Artigo 216).

Nesse Artigo, a Constituição, inclui os sítios de valor paisagístico, paleontológico, ecológico e científico, dentre outros, aos bens patrimoniais brasileiros, ou seja, valores atrelados ao patrimônio natural biótico e abiótico.

No ano de 2000, foi instituído no Brasil o Sistema Nacional de Unidades de Conservação (SNUC), como uma estratégia de proteção do patrimônio natural brasileiro, podendo acontecer de forma integral ou sustentável.

A lei que institui o SNUC declara que UC é um:

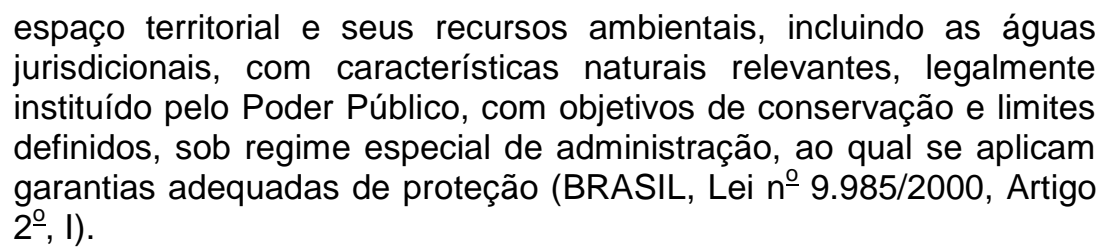

A Lei supracitada esclarece que, a UC Integral tem como objetivo preservar a natureza, sendo admitido apenas o uso indireto dos seus recursos naturais, com exceção dos casos previstos na Lei. Já a UC Sustentável tem como objetivo básico, compatibilizar a conservação da natureza com o uso sustentável de parcela dos seus recursos naturais.

Entretanto, segundo Nascimento et al. (2008) a existência das UCs não têm garantido a proteção dos ambientes naturais, sobretudo à geodiversidade. Muitas UCs no Brasil têm no patrimônio geológico-geomorfológico seu principal atrativo, porém sem haver a devida atenção, não sendo abordado de forma específica, pelo SNUC, e quando o faz é de maneira simplista e superficial, principalmente diante da vulnerabilidade destes ambientes e às ameaças, em sua maioria devido às diversas atividades humanas.

Para Salvan (1994 apud NASCIMENTO et al., 2008), a principal ameaça que pesa sobre o geopatrimônio é a falta de conhecimento sobre sua 
existência. No ensino das Ciências Naturais, o grande público tem, em geral, um conhecimento reduzido sobre os conceitos fundamentais das Geociências. Tal falta de conhecimento constitui um obstáculo importante para conservação da geodiversidade.

Em 2002, a Assembleia Geral das Nações Unidas (AGNU), órgão intergovernamental, plenário e deliberativo da Organização das Nações Unidas (ONU), através da Resolução 57/2544, proclamou a década 2005-2014 como a Década das Nações Unidas da Educação para o Desenvolvimento Sustentável, ou seja, promover, através da educação, a consciência ambiental para proteção da natureza, tanto para geração atual como para as gerações futuras. Para isso, é fundamental um bom conhecimento da biodiversidade e da geodiversidade planetária.

Os conceitos de biodiversidade e geodiversidade surgiram nas décadas de 1980 e 1990, respectivamente, sendo que o conceito de biodiversidade teve uma maior amplitude de aplicações e discussões ao longo dos anos, já o conceito de geodiversidade passou a ser mais trabalhado e divulgado, somente, a partir do final dos anos de 1990, não sendo até então desejavelmente difundido frente à sua importância.

O termo geodiversidade foi citado pela primeira vez, em 1993, na Conferência sobre Geoconservação, realizada em Malvern, Reino Unido. No Brasil, o tema foi inicialmente discutido na comunidade geocientífica, em 2004, no $42^{\circ}$ Congresso Brasileiro de Geologia, em Araxá, Minas Gerais; porém sua consolidação tem se dado recentemente.

$\mathrm{Na}$ literatura, a geodiversidade tem sido aplicada com maior ênfase aos estudos de geoconservação, conservação e gestão do geopatrimônio, ou seja, do patrimônio geológico e geomorfológico; visando destacar e analisar a diversidade de feições, processos e paisagens peculiares, em geossítios, seja por sua beleza cênica, atratividade geoturística, importância científica e/ou pedagógica (GRAY, 2004; BRILHA, 2005; NASCIMENTO et al., 2008; SILVA et al., 2008; COSTA, 2012; GUERRA; JORGE, 2014).

\footnotetext{
${ }^{4}<$ http://www.mma.gov.br/educacao-ambiental/politica-de-educacao-ambiental/item/8074resolu\%C3\%A7\%C3\%A3o-da-onu>
} 
Em 2004, foi publicado pelo geógrafo Murray Gray o primeiro livro dedicado, exclusivamente, ao tema geodiversidade. Para o autor, geodiversidade consiste:

[...] the natural range (diversity) of geological (rocks, minerals, fossils), geomorphological (land form, processes) and soil features. It includes their assemblages, relationships, properties, interpretations and systems (Gray, 2004, p.8).

A CPRM ao lançar o Mapa Geodiversidade do $\mathrm{Brasil}^{5}$, em 2006, defini:

Geodiversidade é a natureza abiótica (meio físico) constituída por uma variedade de ambientes, fenômenos e processos geológicos que dão origem às paisagens, rochas, minerais, águas, solos, fósseis e outros depósitos superficiais que propiciam o desenvolvimento da vida na Terra, tendo como valores intrínsecos a cultura, o estético, o econômico, o científico, o educativo e o turístico (CPRM, 2014).

Os lugares ocupados por ocorrências de um ou mais elementos da geodiversidade são denominados geossítios, tais devem ser bem definidos geograficamente, de particular interesse para o estudo das geociências, e notável sob o ponto de vista científico, educativo, cultural e geoturístico, dentre outros. Os geossítios devem ser conservados por constituírem patrimônio geológico pertencente a todos, e herança dos cerca de 4600 milhões de anos de história da Terra, o que justifica a importância de seu inventário, valoração e geoconservação (GRAY, 2004; BRILHA, 2005; NASCIMENTO et al., 2008; BRILHA; PEREIRA, 2011).

De acordo com Brilha (2005), patrimônio geológico "é definido pelo conjunto de geossítios inventariados e caracterizados em uma dada área ou região" (BRILHA, 2005, p.54).

No Brasil, o inventário e divulgação dos geossítios são feitos pela Comissão Brasileira dos Sítios Geológicos e Paleobiológicos (SIGEP), tal tem a incumbência de reunir os diversos órgãos ou instituições com função, afinidade ou interesse nos geossítios do Brasil.

Em 2002, a SIGEP lançou seu primeiro volume com 58 sítios publicados em nove classificações, pelo seu tipo mais significativo, integrando as

\footnotetext{
${ }^{5}<\underline{\text { http://www.cprm.gov.br/publique/cgi/cgilua.exe/sys/start.htm?infoid=623\&sid=9 }>}$
} 
seguintes categorias: paleontológica, paleoambiental, sedimentológica, geomorfológica, marinha, ígnea, espeleológica, história da geologia, astroblema (SCHOBBENHAUS et al., 2002). Já em 2009, foram publicados mais 40 sítios, acrescentando as categorias: estratigráfica, hidrogeológica, mineração e tectônica (WINGE et al., 2009) ${ }^{6}$.

No geopatrimônio vem ocorrendo, cada vez mais, o destaque do patrimônio geomorfológico, ou seja, dos geomorfossítios (PEREIRA et al., 2004; VIEIRA; CUNHA, 2004; 2006; PEREIRA, 2006; FONTE, 2008; BENTO; RODRIGUES, 2010; VIEIRA et al., 2014).

De acordo com Vieira et al. (2014, p.182),

O património geomorfológico é constituído pelas formas do relevo, depósitos correlativos e processos associados, manifestados a diferentes escalas e aos quais se atribui um conjunto de valores (científico-pedagógico, estético, cultural, ecológico e/ou económico) decorrentes da perceção humana.

Sendo assim, a ênfase ao patrimônio geomorfológico deve-se à necessidade de conservação das geoformas que contém alto valor científico, didático, cênico-paisagístico e/ou geoturístico, dentre outros; como também, a geoconservação das áreas vulneráveis ao risco socioambiental, ressaltando, desta forma, a importância da Ciência Geomorfológica no contexto ambiental. Diante disso, Guerra e Marçal (2006, p.15), destacam a Geomorfologia Ambiental, que "tem como tema integrar as questões sociais às análises da natureza".

Para Viera e Cunha (2006, p.147),

Pelas características que o definem, o Património Geomorfológico, constitui, dentro do conjunto do Património Natural, um grupo bastante vulnerável, porque constitui a base sobre a qual se desenvolvem as actividades humanas e, também, porque se tem vindo a revelar como bastante atractivo para actividades de lazer e turismo, tendo despertado, no seio da comunidade científica, um elevado interesse.

O PNMNI encontra-se na SIGEP em Propostas Aprovadas, com o nome: Complexo Vulcânico de Nova Iguaçu, RJ, dentro da tipologia ígnea

\footnotetext{
${ }^{6}$ Aguarda-se a publicação do volume III <http://sigep.cprm.gov.br/sitios.htm>
} 
(GERALDES, et al. 2006), por ser esta sua característica mais significativa, porém neste trabalho consideraremos, também, as geoformas.

Um dos objetivos da SIGEP é contribuir com a candidatura de futuros Geoparks para Rede Global de Geoparks (GGN) da UNESCO ${ }^{7}$. Para UNESCO, Geopark é um território definido, com singularidades do patrimônio geológico nacional que possam beneficiar a GGN por intermédio de intercâmbio e cooperação.

Os Geoparks visam combinar conservação, desenvolvimento sustentável e participação da comunidade, tendo como propósito, explorar, desenvolver e celebrar as interações entre o patrimônio geológico e todos os outros aspectos de patrimônios naturais, culturais e intangíveis da área (GLOBAL GEOPARK, 2014).

Entretanto, o termo Geopark (ou Geoparque) pode ser utilizado para identificar áreas não pertencentes à $G G N$, porém tais devem conter características peculiares da geodiversidade, de importância internacional, nacional, regional ou local; como também, é necessário que a área sirva ao desenvolvimento sustentável da população local, especialmente através do geoturismo, sendo este um desafio para o PNMNI.

\section{O CHAMADO VULCÃO DE NOVA IGUAÇU}

A diversidade geológico-geomorfológica do PNMNI vem sendo discutida, ao longo dos anos, por vários cientistas que estudaram e estudam a veracidade da existência de indicadores de atividades vulcânicas na região (KLEIN; VIEIRA, 1980a/b; KLEIN et al., 1984; MOTA; GERALDES, 2005; 2006; MOTOKI et al., 2007; 2008; MOTOKI; MOTOKI, 2011; MOTA et al, 2012; DRM/RJ, 2014).

Já em 1954, Lamego constatou ao longo do rio Guandu do Sopé, que se encontra à esquerda do Maciço do Mendanha, a presença de ignimbritos,

\footnotetext{
${ }^{7}<$ http://www.globalgeopark.org/aboutGGN/6398.htm>
} 
rochas provenientes de fluxos piroclásticos. Klein et al. (1984) conceberam essa ocorrência como um outro vulcão da mesma época do Vulcão de Nova Iguaçu, batizado como Chaminé do Lamego.

Em 1977, os geólogos André Vieira e Victor Klein desenvolveram estudos sobre a geologia do Estado do Rio de Janeiro. Ao analisarem fotos aéreas de Nova Iguaçu, constataram ocorrências de rochas vulcânicas que, dispostas de forma circular, cobriam uma extensa área da Serra de Madureira, no Maciço do Gericinó (VIEIRA; KLEIN, 2004).

Durante os anos de 1977 a 1979 os citados cientistas realizaram mapeamentos geológicos e, em 1980, publicaram os resultados dos seus estudos (KLEIN; VIEIRA, 1980a/b).

Em 19 de dezembro de 1979 foi noticiada, na Sessão Extraordinária na Academia Brasileira de Ciências do Rio de Janeiro, a existência de um vulcão no Município de Nova Iguaçu. Assim, foi descoberto um vulcão brasileiro, sendo divulgado na mídia, em 2004, como o Vulcão de Nova Iguaçu, o que aumentou o seu número de visitantes, uma vez que tais características passaram a aguçar a curiosidade das pessoas com relação à possibilidade de conhecerem um vulcão em seu próprio país (KLEIN; VIEIRA, 1980a/b; KLEIN et al., 1984; VIEIRA; KLEIN, 2004).

Posteriormente, pesquisas desenvolvidas por outros geocientistas, confirmaram a hipótese do Vulcão de Nova Iguaçu (GERALDES; NETTO, 2004; SILVEIRA et al., 2005; VALENTE et al., 2005; MOTA; GERALDES, 2005; 2006; ALVES et al., 2006).

Em junho de 2004 foram instalados, pelo Departamento de Recursos Minerais do Estado do Rio de Janeiro (DRM-RJ), no âmbito do projeto Caminhos Geológicos ${ }^{8}$, seis painéis interpretativos no PNMNI, ao longo da Estrada da Cachoeira. O projeto objetiva transformar a linguagem científica em popular e, desta forma, promover a divulgação e proteção do patrimônio geológico estadual (GERALDES; NETTO, 2004; GHIZI et al., 2004; MANSUR et al., 2004; DRM/RJ, 2014).

\footnotetext{
${ }^{8}<$ http://www.caminhosgeologicos.ri.gov.br>
} 
Um painel principal foi instalado na sede administrativa do Parque, apresentando conceitos básicos sobre vulcões e descrevendo as feições que demonstram a existência de processos vulcânicos na região. As outras cinco placas menores foram colocadas em pontos que permitem a identificação das principais feições do Vulcão de Nova Iguaçu, no caminho selecionado (MANSUR et al., 2004).

Entretanto, a partir de 2007, estudos começaram a defender a inexistência do Vulcão, e sim de feições subvulcânicas (MOTOKI et al., 2007; 2008; MOTOKI; MOTOKI, 2011).

Segundo Motoki e Motoki (2011), os materiais identificados como rochas piroclásticas, são interpretados como tufos e brecha de preenchimento de condutos subvulcânicos que foram posicionados por uma profundidade de $3 \mathrm{~km}$ e atualmente estão expostos devido ao soerguimento regional e consequente denudação (MOTOKI et al., 2007; 2008). Para os autores foram totalmente erodidos e transportados os depósitos eruptivos e as rochas vulcânicas do complexo vulcânico de Nova Iguaçu, pela ação do intemperismo ao longo dos milhões de anos.

Essa ideia foi incorporada nos painéis existentes no Parque, do projeto Caminhos Geológicos, como outra interpretação para as rochas. Porém, tais interpretações não diminuem a relevância da área, mas corroboram com a ideia da presença de feições raras e pouco estudadas internacionalmente, sendo assim, indispensável à necessidade de geoconservação do PNMNI.

\section{ATRATIVOS DA GEODIVERSIDADE DO PNMNI}

Dos atrativos da geodiversidade existentes no PNMNI foram selecionados, para este artigo, sete geossítios/geomorfossítios ao longo do Caminho das Águas, com valores: científico, didático e/ou cênico-paisagístico; sendo eles: Pedreira desativada São José, Poço do Escorrega, Ponte sobre o rio Dona Eugênia, Afloramento, Poço das Cobras, Poço do Casarão e Cachoeira do Véu da Noiva (figura 2). Para seleção e interpretação dos pontos 
foram utilizadas as seguintes referências: Motoki et al., 2007; 2008; Mello, 2008; Oliveira et al., 2010; Silva et al., 2011; Guerra; Guerra, 2012; Oliveira, 2013; Oliveira et al., 2013; Oliveira; Costa, 2014; DRM/RJ, 2014.

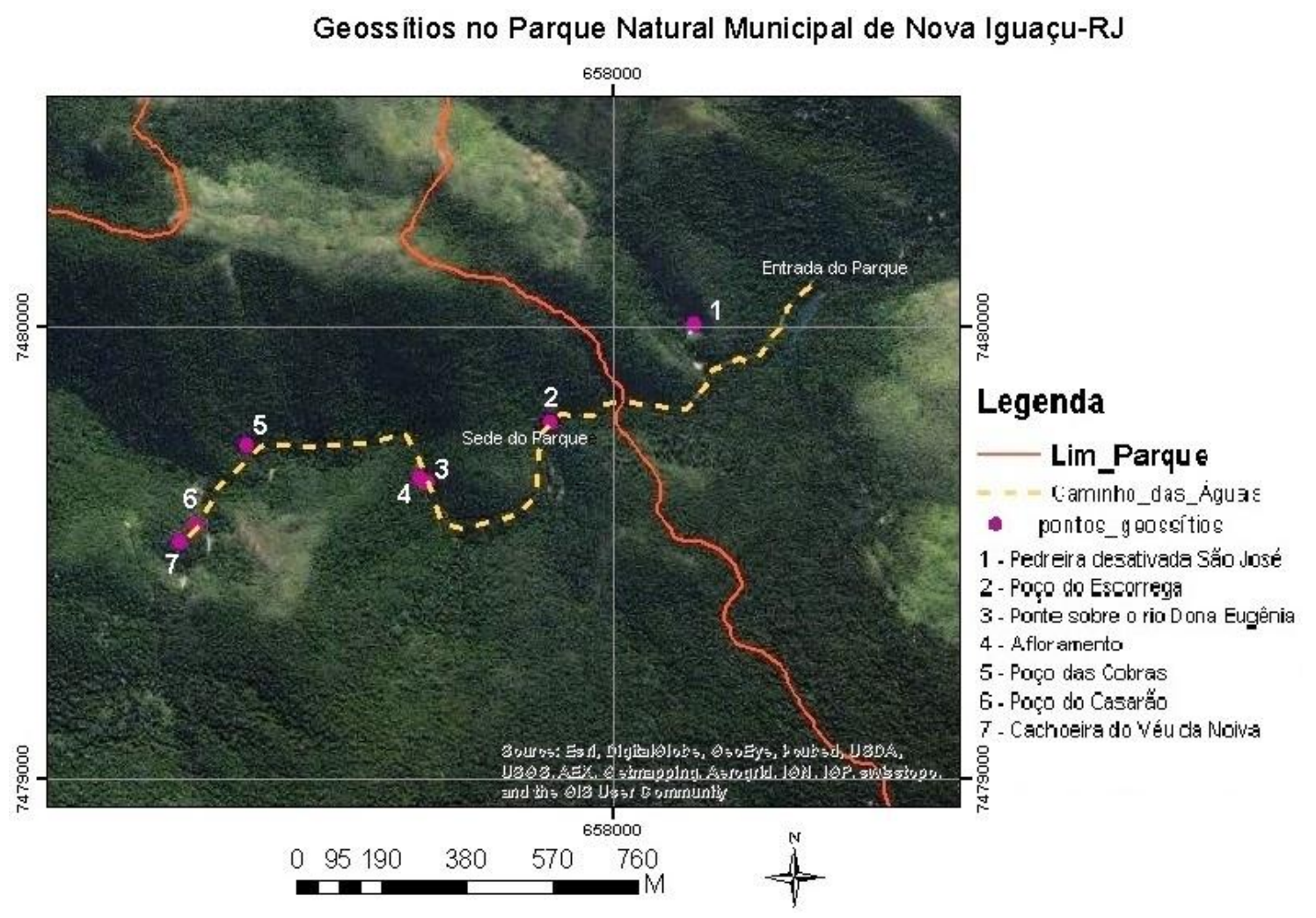

Figura 2 - Localização dos geossítios.

Cerca de 200 m da entrada do Parque está a Pedreira desativada São José, coordenadas UTM 658183 E / $7480006 \mathrm{~N}$ - fuso $23 \mathrm{Sul} /$ WGS $84^{9}$, encerrada há mais de 40 anos (figuras 2; 3). A pedreira desativada forma um belíssimo anfiteatro, composto majoritariamente pela rocha sienito, que é de origem ígnea plutônica, alcalina, contendo, principalmente, os minerais: feldspatos e anfibólios. A formação do sienito se dá pela cristalização do magma em profundidade na câmara magmática. Com a denudação, isto é, remoção da superfície por efeito erosivo, o sienito foi exposto de forma

\footnotetext{
${ }^{9}$ Todas as coordenadas apresentadas neste artigo foram levantadas com aparelho GPS, por meio do método de posicionamento absoluto, e tais estão referenciadas no fuso UTM 23 Sul, datum WGS 84
} 
nivelada, e aflorado, posteriormente, pela mineração de brita, formando um magnífico paredão rochoso (figura 3).

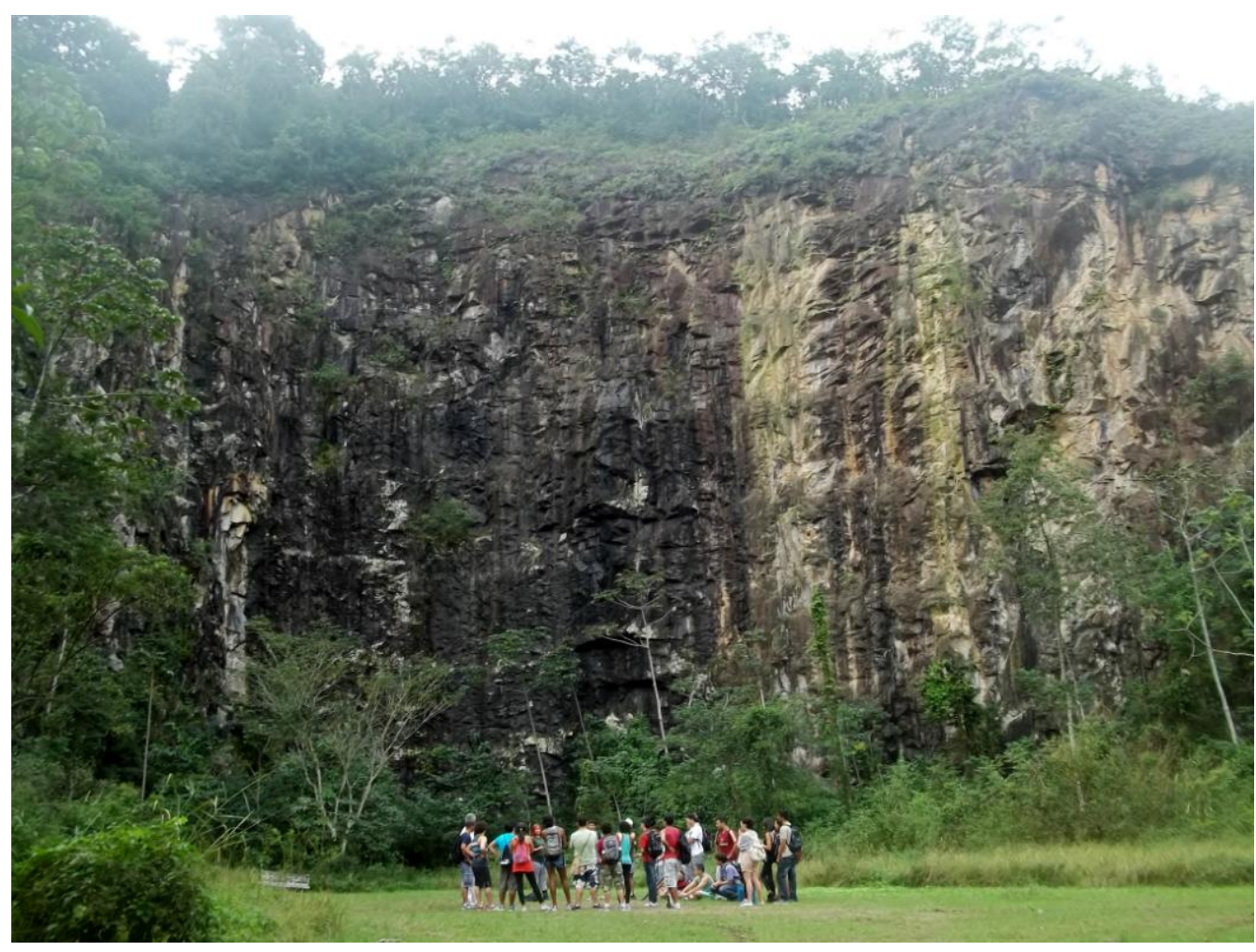

Figura 3 - Pedreira desativada São José, PNMNI. Trabalho de campo realizado no âmbito da 1a Semana do Geógrafo da FEBF-UERJ (foto: Flávia Lopes Oliveira, maio/2013).

Seguindo mais $400 \mathrm{~m}$ encontra-se, à esquerda, o Poço do Escorrega, coordenadas UTM $657861 \mathrm{E} / 7479790 \mathrm{~N}$ (figuras 2; 4). O poço é formado pela integração de processos endógenos e exógenos, à medida que, a presença de diques de traquito, estruturas tabulares encaixadas em brecha, propicia a abertura de poços superficiais pela ação erosiva das águas fluviais e pluviais (figura 4 - tracejados). Tal feição aparece não apenas neste ponto, mas também em outras localidades do Parque, ao longo do rio Dona Eugênia.

Prosseguindo pelo Caminho das Águas, após a sede do Parque, está a Ponte sobre o rio Dona Eugênia, coordenadas UTM 657622 E / 7479604 N (figuras 2). Esta edificação permite contemplar o leito rochoso do rio em seu 
curso médio-superior, além de tornar visível o limite entre os Municípios de Mesquita e Nova Iguaçu.

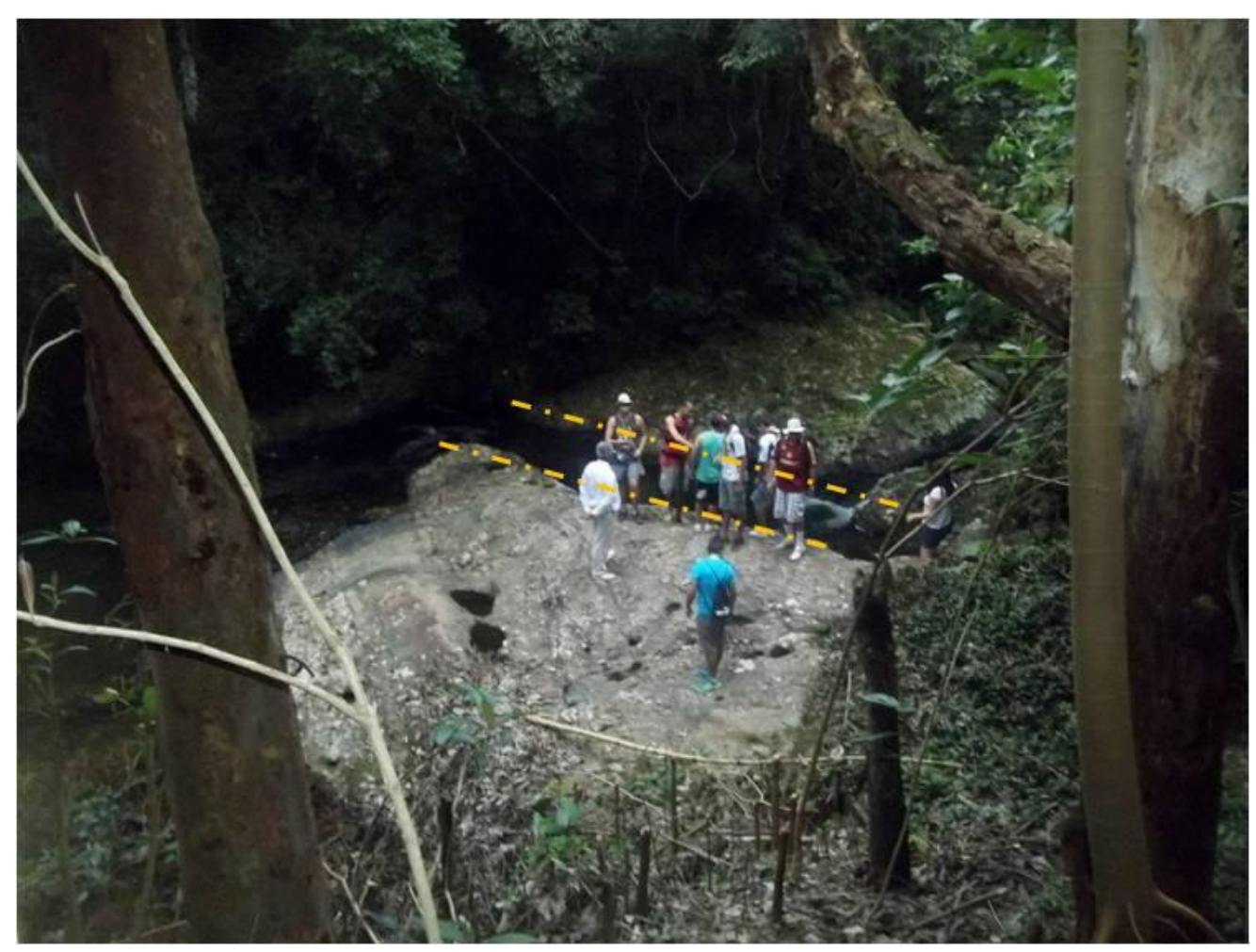

Figura 4 - Poço do Escorrega, PNMNI. Trabalho de campo realizado no âmbito da $1^{\text {a }}$ Semana do Geógrafo da FEBF-UERJ (foto: Flávia Lopes Oliveira, maio/2013).

Logo após a ponte, aproximadamente 100 metros, à esquerda, observase um Afloramento, coordenadas UTM 657571 E / 7479666 N (figura 2), identificado pela placa do projeto Caminhos Geológicos (DRM/RJ) intitulada Lavas e brechas vulcânicas. Neste geossítio encontram-se traquitos e brechas já em estado avançado de intemperismo. Na parte inferior do afloramento observa-se um material mais homogêneo, consistente e de textura microgranular (traquito). Aproximadamente $120 \mathrm{~cm}$ acima está uma camada de brecha, sendo esta de aspecto mais heterogêneo, composta por fragmentos de rochas (bombas) ligadas por uma massa mais fina (matriz); e aproximadamente $100 \mathrm{~cm}$ acima, aparece outra camada de traquito.

Prosseguindo pelo Caminho, do lado direito está o Poço das Cobras, coordenadas UTM 657209 E / 7479710 N (figura 2). Nele observa-se, além de 
uma pequena queda d'água com cerca de $4 \mathrm{~m}$ de altura, uma piscina natural formada pela ação das águas do rio sobre o leito rochoso. Neste geomorfossítio pode ser contemplado, ainda, um didático contato litológico de sienito e brecha, o que indica a possível ocorrência de falha geológica.

Mais adiante, após o antigo Casarão, do lado esquerdo, avista-se o Poço do Casarão, coordenadas UTM 657083 E / 7479562 N (figuras 2; 5). Nele pode ser contemplada uma aprazível paisagem geomorfológica com presença de piscina natural e pequena cachoeira. Neste sítio, observam-se, também, feições com características excêntricas. São formas lineares (figura 5 - linhas amarelas) e salientes que se destacam em relação às outras. Porém, tanto os núcleos como as estruturas lineares são constituídos pelo sienito. A rocha do núcleo se desgasta mais facilmente do que a das bordas, propiciando a formação das chamadas marmitas de erosão (figura 5 - círculos vermelhos). Para Motoki et al. (2008), a aparente inversão do relevo pode ser originada por um processo intempérico denominado case hardening.

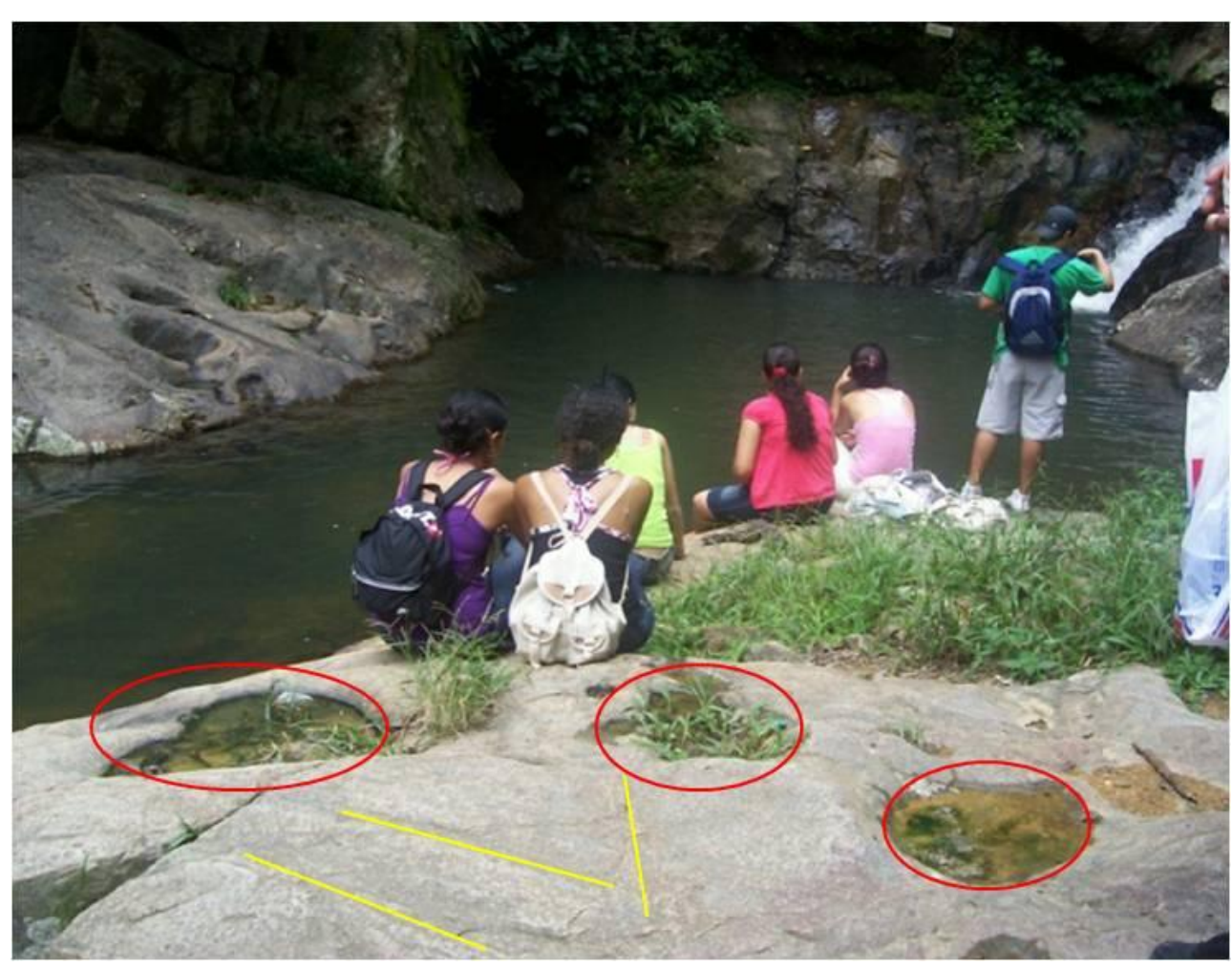

Figura 5 - Poço do Casarão. Trabalho de campo com alunos do curso de Licenciatura em Geografia da FEBF-UERJ (foto: Flávia Lopes Oliveira, fevereiro/2009). 
Por fim, situado nos fundos do Casarão, encontra-se um exuberante geomorfossítio, a Cachoeira do Véu da Noiva, coordenadas UTM 657038 E / $7479525 \mathrm{~N}$ (figuras 2; 6). Ela apresenta uma queda d'água com cerca de $55 \mathrm{~m}$ de altura, que desce em um relevo escarpado, formando um caminho esculpido pelas águas que deságuam em uma piscina. Seu acesso se dá pelo leito do rio, sendo assim pouco explorada em atividades educativas, porém é um ponto de grande atratividade, utilizado em roteiros de passeios realizados por agências de turismo no Parque (figura 6). É importante ressaltar que, do topo da cachoeira tem-se uma das mais belas e didáticas vistas do vale do rio Dona Eugênia.

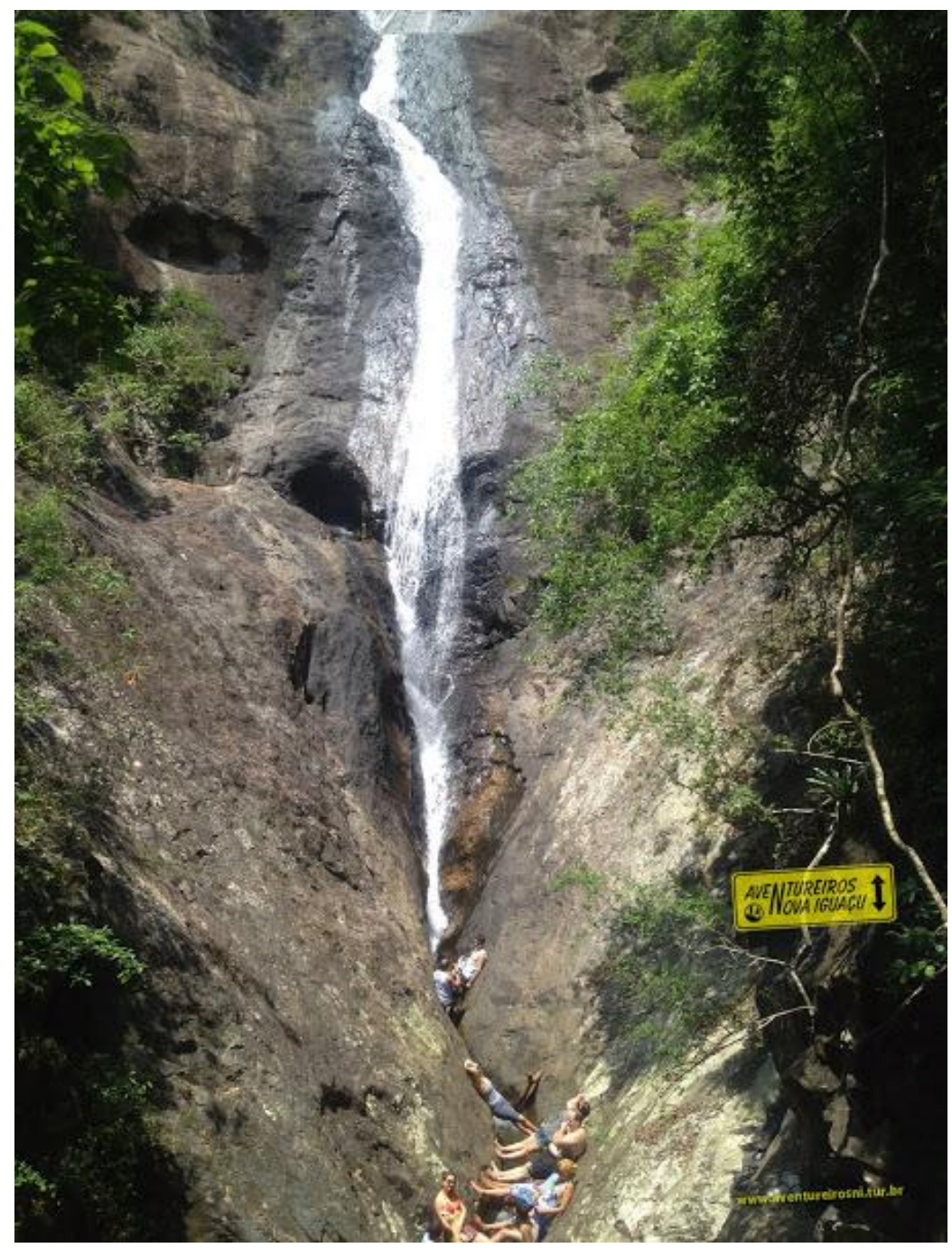

Figura 6 - Cachoeira do Véu da Noiva. Atividade recreativa realizada pela empresa de turismo: Aventureiros de Nova Iguaçu, em fevereiro/2014 (foto: $<$ http://www.aventureirosni.tur.br/>). 


\section{CONSIDERAÇÕES FINAIS}

Com bases nas discussões e nos dados apresentados neste artigo, pode-se concluir que o PNMNI é um importante patrimônio natural abiótico, pois reúne geossítios raros no Brasil e de elevado valor científico, didático e cênico-paisagístico. Tais características confirmam a necessidade de criação de metodologias de geoconservação e gestão de uma das mais importantes áreas protegidas fluminense.

\section{REFERÊNCIAS BIBLIOGRÁFICAS}

ALVES, A.P.R., MOTA, C.E.M., GERALDES, M. C. Fácies vulcânicas no Maciço Alcalino do Mendanha: registros de processos extrusivos no Cretáceo no Brasil. Anais do $7^{\circ}$ Simpósio do Cretáceo do Brasil. Serra Negra-SP, abril 2006. 47p.

BENTO, L.C.M; RODRIGUES, S.C. Geoturismo e geomorfossítios: refletindo sobre o potencial turístico de quedas d'água - um estudo de caso do Município de Indianópolis/MG. Revista Geografia Acadêmica, v.4, n.2, 2010. p.96-104.

BRASIL. Constituição da República Federativa do Brasil, Distrito Federal, 1988.

BRASIL. Lei 9.985, de 18 de julho de 2000. Institui o Sistema Nacional de Unidades de Conservação da Natureza - SNUC. Brasilha/DF.

BRILHA J. Património geológico e geoconservação: a conservação da natureza na sua vertente geológica. Viseu: Palimage Editores, 2005. 190p.

BRILHA J.; PEREIRA, P. (eds.) Património geológico: geossítios a visitar em Portugal/Geological heritage: geosites to visit in Portugal. Braga: Universidade do Minho, 2011. 137p.

COSTA, N.M.C. O relevo carioca: uma paisagem de contrastes naturais. In: ZEE, D. (org.). Barra da Tijuca: natureza \& cidade. Rio de Janeiro: Andrea Jakobsson Estúdio Editorial, 2012. p.50- 81.

CPRM - Companhia de Pesquisa de Recursos Minerais. Mapa geodiversidade do Brasil, $2006 . \quad$ Disponível em: $<$ http://www.cprm.gov.br/publique/cgi/cgilua.exe/sys/start.htm?infoid=623\&s id=9\#geodiversidade $>$ [Acesso em: 05.05.2014]. 
DRM/RJ - Departamento de Recursos Minerais do Estado do Rio de Janeiro. Projeto caminhos geológicos. Disponível em: <http://www.caminhosgeologicos.rj.gov.br/> [Acesso em 12.01.2014].

FORTE, J.P. Patrimônio geomorfológico da unidade territorial de Alvaiázere: inventariação, avaliação e valorização. 295f. Dissertação (Mestrado em Geografia) - Departamento de Geografia, Universidade de Lisboa. Portugal. 2008.

GERALDES, M.C. PIMENTEL, L.S.; SILVA, F.L.; FERREIRA NETO, W.D. O complexo vulcânico de Nova Iguaçu: subsídios para a preservação de um monumento geológico. Proposta de descrição de sítio geológico do Brasil para registro no patrimônio mundial da humanidade (UNESCO). SIGEP Comissão Brasileira de Sítios Geológicos e Paleobiológicos, 2006. Disponível em: <http://sigep.cprm.gov.br/quadro.htm> [Acesso em: 05.05.2014].

GERALDES, M.C., NETTO, A.M. Elaboração de placas do Geoparque do Vulcão de Nova Iguaçu-RJ: a utilização de linguagem popular para explicar a construção de um edifício vulcânico. Anais do XLII Congresso Brasileiro de Geologia. Araxá, SBG, CD, outubro 2004. 1p.

GHIZI, A.; MANSUR, K.; VIEIRA, A.C. Projeto caminhos geológicos: o ponto de interesse geológico do Vulcão de Nova Iguaçu. Anais do XLII Congresso Brasileiro de Geologia. Araxá, SBG, CD, outubro 2004. 1p.

GLOBAL GEOPARK - Global Geoparks Network. Disponível em: <http://www.globalgeopark.org/index.htm> [Acesso em: 05.05.2014].

GRAY, M. Geodiversity: valuing and conserving abiotic nature. Londres: John Wiley \& Sons Ltd, 2004. 434p.

GUERRA, A.J.T.; JORGE, M.C.O. Geomorfologia aplicada ao turismo. In: ARANHA, R.C.; GUERRA, A.J.T. (orgs.) Geografia aplicada ao turismo. São Paulo: Oficina de Textos, 2014. p.56-80.

GUERRA, A.J.T; MARÇAL, M.S. Geomorfologia ambiental. Rio de Janeiro: Bertrand Brasil, 2006. 192p.

GUERRA, A.T; GUERRA, A.J.T. Novo dicionário geológico-geomorfológico. 11. ed. Rio de Janeiro: Bertrand Brasil, 2012. 648p.

IPHAN - Instituto de Patrimônio Histórico e Artístico Nacional. Disponível em: $<$ http://portal.jphan.gov.br/portal/montarPaginalnicial.dos $\left[\begin{array}{lll}\text { Acesso em } & \text { em }\end{array}\right.$ 05.05.2014].

KLEIN, V.C.; VALENÇA, J.G.; VIEIRA, A.C. Ignimbritos do vulcão de Nova Iguaçu e da "Chaminé do Lamego", Rio de Janeiro. Anais do XXXIII Congresso Brasileiro de Geologia. Rio de Janeiro, outubro 1984. 
KLEIN, V.C.; VIEIRA, A.C. Uma chaminé vulcânica na Serra de Madureira, Nova Iguaçu, Rio de Janeiro. Academia Brasileira de Ciências, Rio de Janeiro, v.1, n.52, 1980a. p.200.

KLEIN, V.C.; VIEIRA, A.C. Vulcões do Rio de Janeiro: breve geologia e perspectivas. Mineração Metalurgia, Ouro Preto, v.419, 1980b. p.44-46.

LAMEGO A.R. Uma chaminé vulcânica no Distrito Federal. Notas preliminares e estudos da Divisão de Geologia e Mineralogia, Rio de Janeiro. 1954, 12p.

MANSUR, K.; GHIZI, A.; GUEDES, E.; MEDEIROS, F.; NOGUEIRA, G.; BARBOSA, M.; NETTO, A. M.; RAGATKY, D.; GERALDES, M. C.; PIMENTEL, L.S.; ZALAN, F. A transformação da linguagem científica em popular na elaboração de placas descritivas de pontos de interesse geológico: o caso do geoparque do Vulcão de Nova Iguaçu-RJ. Anais do XLII Congresso Brasileiro de Geologia. Araxá, SBG, CD, outubro 2004. 1p.

MELLO, F.A.P. Ordenamento da malha de trilhas como subsidio ao zoneamento ecoturístico e manejo da visitação no Parque Natural Municipal de Nova Iguaçu-RJ. 192f. Dissertação (Mestrado em Geografia) Programa de Pós Graduação em Geografia, Universidade do Estado do Rio de Janeiro, UERJ. Brasil. 2008.

MOTA, C.E.M., GERALDES, M.C. A classificação de brechas magmáticas e sua implicação na evolução do complexo alcalino de Nova IguaçuRJ. Geociências, Rio Claro. v.25, 2006. p.37-48.

MOTA, C.E.M.; GERALDES, M.C. As brechas tectônicas no maciço do Mendanha, Nova Iguaçu - RJ: registros de processos de colapso por pressão de magma. Anais do III Simpósio de Vulcanismo e Ambientes Associados. Cabo Frio-RJ, agosto 2005. 6p.

MOTA, C.E.M.; GERALDES, M.C.; SOUSA, M.A.; MANE, M.A.E. Estrutura subsuperficial do Complexo Alcalino do Mendanha, Rio de Janeiro, por integração de dados geológicos e gravimétricos. REM-Revista Escola de Minas, Ouro Preto, v.65, n.4, 2012.p.491-499.

MOTOKI, A.; MOTOKI, K.F. Origem dos relevos do maciço Mendanha, RJ, movimento de falhas ou erosão diferencial?: análises geomorfológicas por seppômen e sekkokumen com base do ASTER GDEM. Anais do $13^{\circ}$ Simpósio Nacional de Estudos Tectônicos. Campinas, SBG, CD, maio 2011. p.378-381.

MOTOKI, A.; SICHEL, S.E.; SOARES, R.S.; AIRES, J.R.; SAVI, D.C.; PETRAKIS, G.H., MOTOKI, K.F. Rochas piroclásticas de preenchimento de condutos subvulcânicos do Mendanha, Itaúna e Ilha de Cabo Frio, RJ, e seu processo de formação com base no modelo de implosão de conduto. Geociências, Rio Claro. v.27, n.3, 2008. p.451-467. 
MOTOKI, A.; SOARES, R.; NETTO, A.M.; SICHEL, S.E.; AIRES, J.R.; LOBATO, M. Reavaliação genética do modelo do Vulcão de Nova Iguaçu, RJ: origem eruptiva ou intrusão subvulcânica? REM-Revista Escola de Minas, Ouro Preto, v.60, n.4, 2007. p.583-592.

NASCIMENTO, M.A.L.; RUCHKYS, U.; MANTESSO-NETO, V. Geodiversidade, geoconservação e geoturismo: trinômio importante para a proteção do patrimônio geológico. São Paulo: SBGEO, 2008. 82p.

OLIVEIRA, F.L. Percepção e geografia física: um estudo no Parque Natural Municipal de Nova Iguaçu, RJ. Anais do XIV EGAL - Encuentro de Geógrafos de América Latina. Lima, abril 2013. 16p.

OLIVEIRA, F.L.; COSTA, N.M.C. Educação ambiental e diversidade geológicogeomorfológica: bases para geoconservação do Parque Natural Municipal de Nova Iguaçu, RJ, Brasil. Anais do I Encontro Luso-Brasileiro de Património Geomorfológico e Geoconservação. Coimbra, fevereiro 2014. p. 89-95.

OLIVEIRA, F.L.; SILVA, C.M.A.; COSTA, N.M.C. Trabalho de campo no Caminho das Águas, Parque Natural Municipal de Nova Iguaçu/RJ: proposta de roteiro ambiental e subsídio para conservação do patrimônio natural. Anais do II Congresso Nacional de Planejamento e Manejo de Trilhas/l Colóquio Brasileiro para a Red Latinoamericana de Senderismo. Rio de Janeiro: Sirius-UERJ, outubro 2013. p.1182-1202.

OLIVEIRA, F.L.; SILVA, C.M.A.; MELLO, F.A.P. Proposta de um roteiro didático ambiental para trabalho de campo no Parque Natural Municipal de Nova Iguaçu, RJ. Anais do VI UFRJ Ambientável. Rio de Janeiro, outubro 2010. $9 \mathrm{p}$.

PEREIRA, P.; PEREIRA, D.I.; ALVES, M. Paisagens culturais portuguesas como património geomorfológico. Resumos do II Congresso Nacional de Geomorfologia - Geomorfologia, Ciência e Sociedade. Associação Portuguesa de Geomorfólogos, APGeom, Coimbra, novembro 2004. p.67.

PEREIRA, P.J.S. Patrimônio geomorfológico: conceptualização, avaliação e divulgação. Aplicação ao Parque Natural de Montesinho. 395f. Tese (Doutorado em Ciências) - Escola de Ciências, Universidade do Minho, Braga. Portugal. 2006.

PREFEITURA DA CIDADE DE NOVA IGUAÇU - Plano de manejo extensivo do Parque Natural Municipal de Nova Iguaçu, vols. I, II, III. ABTEC Engenharia Sanitária e Ambiental Ltda - Prefeitura Municipal de Nova Iguaçu - Instituto Estadual de Florestas - Fundo Estadual de Controle Ambiental, Nova Iguaçu, 2000.

SCHOBBENHAUS, C.; CAMPOS, D.A.; QUEIROZ, E.T.; WINGE, M.; BERBERT-BORN, M.L.C. (Eds.). Sítios geológicos e paleontológicos do 
Brasil. Brasília: Comissão Brasileira de Sítios Geológicos e Paleobiológicos - SIGEP, 2002. 554p.

SILVA, C.M.A.; OLIVEIRA, F.L.; MELLO, F.A.P. Trabalho de campo como método de ensino na educação ambiental: o caso do Parque Natural Municipal de Nova Iguaçu, RJ. Anais do II Congresso Nacional de Educação Ambiental. João Pessoa: Editora Universitária da UFPB, v.4, outubro 2011. p.1220-1227.

SILVA, C.R; RAMOS, M.AB.; PEDREIRA, A.J.; DANTAS, M.E. Começo de Tudo. In: SILVA, C.R. (Org.). Geodiversidade do Brasil: conhecer o passado para entender o presente e prever o futuro. Rio de Janeiro: CPRM, 2008. p.11-20.

SILVEIRA, L.S.; DUTRA, T.; VALENTE, S.C.; RAGATKY, D.C., 2005. Modelos eruptivos preliminares para o Complexo Vulcânico de Nova Iguaçu, RJ. Anais do III Simpósio de Vulcanismo e Ambientes Associados. Cabo Frio-RJ, agosto 2005. 5p.

UNESCO - Organização das Nações Unidas Para a Educação, a Ciência e a Cultura. Convenção para a proteção do patrimônio mundial cultural e natural. Paris: UNESCO, 1972.

VALENTE, S.C.; MELLO, E.F.; PALERMO, N. Geologia de uma porção do complexo vulcânico de Nova Iguaçu limítrofe à área de lavra da pedreira Vigné, Nova Iguaçu, RJ. Relatório técnico do Projeto TAC Nova Iguaçu: Ministério Público, 2005. 28p.

VIEIRA A.; CUNHA L. Património geomorfológico - de conceito a projecto. O Maciço de Sicó. Publicações da associação portuguesa de geomorfólogos, APGeom, v.3, 2006. p.147-153.

VIEIRA A.; CUNHA L. Património geomorfológico: tentativa de sistematização. Anais do III Seminário Latino Americano de Geografia Física, Puerto Vallarta, México, CD-Rom, abril 2004. p.14.

VIEIRA, A.C.; KLEIN, V.C. Vulcão de Nova Iguaçu, o vulcão brasileiro. Cartilha. CREA-RJ, 2004.10p.

VIEIRA, A; FIGUEIRÓ, A.S.; CUNHA, L. 2014. Metodologia de avaliação do património geomorfológico: aplicação à Serra de Montemuro (Portugal). Anais do I Encontro Luso-Brasileiro de Património Geomorfológico e Geoconservação, Coimbra, fevereiro 2014. p.181-187.

WINGE, M.; SCHOBBENHAUS, C.; SOUZA, C.R.G.; FERNANDES, A.C.S.; QUEIROZ, E.T.; BERBERT-BORN, M.L.C.; CAMPOS, D.A. (Eds.). Sítios Geológicos e Paleontológicos do Brasil. Brasília: Comissão Brasileira de Sítios Geológicos e Paleobiológicos - SIGEP, v. 2, 2009. 515p. 